OPTIMUM. STUDIA EKONOMICZNE NR 5 (65) 2013

Urszula WIDELSKA ${ }^{1}$

\title{
MARKETING BARRIERS TO E-HEALTH IN THE PODLASKIE PROVINCE
}

\begin{abstract}
Summary
The article undertakes the problem of a marketing scope of e-health, combined with the use of ICT in the health care system. The study focuses on the needs of patients - the main consumers of medical services. The purpose of the article is to identify marketing barriers to e-health services from the perspective of patients and the medical community. To analyze the problem an example of the Podlaskie Province was used.
\end{abstract}

Key words: e-health, marketing, Podlaskie Province

\section{Introduction}

E-health is a relatively recent phenomenon. It is more often analyzed in terms of implementing broadly defined innovation of ICT into the health care system and the various medical facilities. In a broader sense, e-health means activities aimed at improving the quality of health services, improving the quality of patient services and improving access to health services. Taking into account the wider context of e-health, building the right relationships between health care facilities and patients, recipients of medical services, seems to be a particularly important aspect. The aim of the study is to identify marketing barriers to e-health from the perspective of the patient and the medical community based on the example of the Podlaskie Province. To achieve the objective, the example of Podlaskie Province was used. The conclusions were supported by the research results included in the final report on the area of e-health in the Podlasie Province within the project "E-Poland - development trends of the information society" [Widelska at al., 2011]2, which was co-created by the author of this paper.

\footnotetext{
${ }^{1}$ Urszula Widelska, Ph.D. - Faculty of Management, Bialystok University of Technology; e-mail: widelskau@wp.pl.

2 The object of the research was the area of application of Information and Communication Technology in healthcare - e-health. The following research areas were distinguished: the analysis of e-health in the Podlaskie Province, in comparison with other regions of the country and Europe; identification of development factors of e-health in the Podlaskie Province including barriers and determinants influencing this development; assessment of the prospects for the development of e-health in the Podlaskie Province. The main objective of the study was to determine the current state of information society development in the area of health care in the Podlaskie Province, with particular em-
} 


\section{The essence of e-health - european and national context}

E-health is the use of ICT in the health care system. By assumption, it is based on the cooperation of two fields - broadly defined health care and modern information systems. The modern health care system requires continuous improvement of processes affecting the availability, efficiency and quality of health services. It is particularly important to increase access to preventive tests, make changes in traditional systems of patient service and support all activities and processes, whose aim is to take into account often unfavorable demographic trends and the trends towards an overall improvement in the living standard of citizens.

E-health has become a subject of interest to the European Commission. In the discussion of the analyzed issues in May 2003, the definition of e-health was presented as the use of modern information and communication technologies to satisfy the needs of citizens, patients, professionals in the field of health care, health care providers and policy makers [Widelska at al., 2011]. As the most important arrangements of the diagnosis of the development of e-health in Europe, influencing the need for urgent action, the EC acknowledged: [Widelska at al., 2011]:

- $\quad$ the increase in demands to health care and social welfare services resulting from the "aging" of society;

- the increase in income and level of education;

- increasing expectations of citizens who in the current EU social model demand the best health care and reducing disparities in access to high quality medical care;

- $\quad$ increasing mobility of patients and physicians within better functioning internal market in the EU;

- $\quad$ the need to reduce a burden of diseases and the prevention of risks of emerging diseases (e.g. SARS);

- $\quad$ early detection of diseases and quicker response and minimization of the risk of these diseases;

- difficulties of public authorities to connect investments in technologies with investments in complex organizational changes needed to use the potential of the implemented technologies;

- the need to reduce accidents at work and the risk of occupational diseases;

- the management of all the resources of health data that must be available in a safe, friendly, and fast way and in a place where they are needed, and processed in an efficient manner for administrative purposes;

- $\quad$ the need to provide the best possible health care under limited budgetary resources.

In April 2004, the European Commission published "The EU Action Plan" (European Union Action Plan) for a European e-Health Area. The document specifically refers to the following activities [Communication From ...., 2004]:

phasis on IT technologies, which are the subject of research of the EU institutions and to identify the main development barriers. 
1. Gaining independence of health care consumers (patients and healthy citizens) to enable them to manage their well-being through access to qualified sources of health information, as well as through active participation in the prevention of diseases, allowing patients to participate (with better knowledge and responsibility) in the process of care and rehabilitation through intelligent monitoring systems, as well as by the appropriate and personalized medical information.

2. Supporting professionals by providing them with access to relevant and current information at the time of such need, to new tools for better risk management and systems to acquire current biomedical knowledge.

3. Supporting departments and managers of health care by assisting in the appropriate management of the ongoing reorganization of health care systems.

The process of development of e-health in Poland has been slow. Using published in June 2006 results of the sixth edition of measurements of the development of health care services on-line conducted by Capgemini, Poland was the last on the list out of eighteen countries covered by the survey [Widelska at al., 2011].

The development of e-health in Poland is suppoted by a large, compared to other countries of the European Union, proportion of Internet users looking for information on health services (63.2\%). However, many other disparities in the development of this sphere of heatlh care in comparison with other European are noticed. Using the results of the research carried out at the request of the European Commission in 2008, the following conclusions can be drawn (see Figure 1) [Benchmarking ICT...., 2007; Europe's Digital Competitiveness Report, 2010]:

1. Poland was considered a "straggler" within the implementation of e-health, due to the results below the EU-27 average for most indicators included in the study. It concerned both the availability of ICT infrastructure (computer, the Internet) and the use of ICT in various areas related to e-health.

2. Approximately $50 \%$ of the Polish GP practices were using administrative data of a patient in an electronic form, whereas the patient's medical records (in whatever form) in an electronic form were in about $40 \%$ of practices.

3. In Poland, the computers were used during medical consultations only to a very limited extent (11\% of practices). This percentage has remained far behind the EU-27 average at $66 \%$. The use of decision support systems was the exception rather than the rule. $19 \%$ of Polish physicians used decision support systems, applied both in the diagnosis and to issue recommendations, which was one of the lowest rates in the EU-27. 
FIGURE 1.

The use of ICT infrastructure in a group of family doctors in Poland and in the EU countries

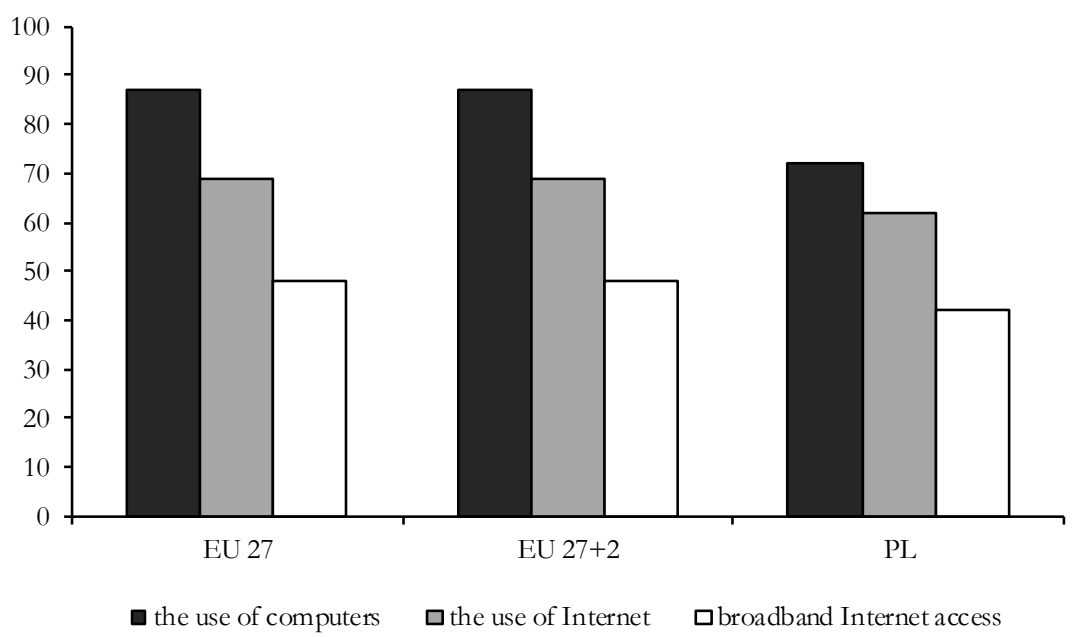

Source: [Benchmarking ICT..., 2007].

It should be noted that Poland is one of the few countries that does not have a National Strategy for the Development of e-health, although some of its elements (except for telemedicine) began to be implemented. Also the lack of regulation on a crossborder exchange of medical data of patients, the lack of a system of certification for websites of online pharmacies, the lack of training system for mid level medical personnel can be seen. The development of Polish telemedicine is also limited by the lack of appropriate legal regulations and the high cost of implementation, but also the lack of demand from service providers. Regarding the use of e-learning in the field of health sciences, the lack of an offer concerning nursing, public health and dentistry is particularly noticeable [Widelska at al., 2011].

\section{Marketing context of e-health}

It should be emphasized that modern medical services market is subject to many changes. In the market, more and more non-public medical facilities are established, thereby competition is increasing. The process can be described as progressive and increasingly important. Providing health services on market basis results in the fight for the customer - the recipient of medical services. Health care is a system whose main goal is to meet the health care needs of the population, which, due to social and demographic transformations, are subject to constant changes [Stanisz-Bush, 2010, p. 2]. Speaking of the needs of citizens within e-health, it should be emphasized that in spite 
of the fact that people are healthier and live longer, the demand for health care services continues to increase. Also the circumstances of these transformations change, which is associated with [Good Practice Guide E-Health..., 2007]:

- the development of medical technologies (increased possibilities),

- the aging of the population (a growth of the needs),

- increased mobility of people (which changes the needs for the provision of health care services).

The idea of e-health is conducive to building proper relationships with customers recipients of medical services. E-health, due to the strong involvement of new information and communication technologies into a process of patient care services, can in particular contribute to a stronger exposure and strengthening the role of information, which often determines the quality of the relationships between the patient and the medical facility. Informational context of e-health can directly translate into:

- the image of the medical facility in the patient's awareness,

- more effective promotion of the medical facility,

- $\quad$ building the knowledge potential of medical personnel (e-health implementation requires the development of specific competencies).

In addition to the informational aspect, the aspect of quality is particularly important. Concerning the quality, it is referred to the quality of medical services, but also the quality of patient care. Research on e-health strongly emphasize the marketing context of the analyzed project. In the period between December 2008 and May 2009, Gartner on behalf of the Minister of Health and Social Affairs of Sweden conducted in six European countries (the Czech Republic, France, the Netherlands, Sweden, Spain and the United Kingdom) a detailed study on the potential benefits from the use of e -health. The research results were published in the document entitled "eHealth for a Healthier Europe!". The authors of the report singled out thirty-seven potential benefits of the use of innovative solutions in health care. The most important include [E-health for Europe!..., 2009]:

- significant reduction of duplicate laboratory tests;

- $\quad$ reduction in the number of visits to primary care physicians;

- reduction of misadministration of medication;

- $\quad$ shorter stay in hospital;

- reduction of cases of wrong prescriptions or dosage of medications;

- reduction of the risk of adverse effects during treatment;

- $\quad$ reducing the cost of each prescription;

- $\quad$ shortening the time for administration to fill forms;

- $\quad$ reduction of the waiting time for an appointment or treatment.

It should be noted that e-health should be considered on two levels. The first level is building relationships with patients in the context of the needs of the society. The second level is the use of e-health in a medical facility. Referring to the first of the levels, it should be emphasized that the benefits to the society are connected with high costs borne by the system. In 2009, at the request of the European Commission, a report on the socio - economic benefits from the use of a electronic 
health record (EHR) and electronic transfer of prescriptions was prepared. The authors of the document, entitled "The socio-economic impact of interoperable electronic health record (EHR) and ePrescribing systems in Europe and beyond - Final study report" [The socio-economic impact..., 2009], calculated that the use of these solutions has begun to bring measurable benefits that exceed the costs of implementing the changes from the sixth year, and benefits grow rapidly in subsequent years of the use of the systems. Referring to the social aspect of the needs, the following facts should be considered [Widelska at al., 2011]:

- a rapid growth of broadband access;

- there is availability for training projects funded from the EU's resources on learning how to use computers and the Internet for groups who do not have knowledge of IT technologies;

- $\quad$ an increasing interest of the Polish society associated with using the Internet to search for information on health;

- a growing number of computer hardware, which is in the possession of private users and companies in Poland;

- $\quad$ an increase in the role of information societies;

- a visible increase in public awareness of the benefits of modern technologies in the field of health care.

Referring to the e-health as a factor in strengthening the process of marketing management of a medical facility, it is important to take into account the following aspects of development:

- there is an increase in the awareness of managers of health care facilities of long-term benefits resulting from the implementation of new solutions;

- $\quad$ an increase in awareness of the benefits associated with the use of IT systems in health care;

- visible readiness of medical personnel to improve qualifications within the use of IT technologies.

E-health is not only a response to the changing social needs. The marketing aspect of e-health is very broad. First of all, it enables to build a new quality of relationships with patients. It is an undertaking that can support the creation of a positive image of medical facilities in the minds of health care service recipients. In addition, e-health is a tool that improves the system of marketing management in a medical facility.

\section{Barriers to e-health in the opinion of medical communities ${ }^{3}$}

Referring to marketing barriers to e-health in the Podlasie Province, those aspects of e-health have been analyzed which have a direct impact on building the relationships between the medical facility and the patient. As the study showed, representatives of se-

\footnotetext{
${ }^{3}$ On the basis of in-depth interviews of managers of health care facilities, particularly hospitals, and the results of focus group interviews (FGI) among managers of health care, representatives of the medical services, representatives of the private health care institutions in the Podlasie region [Widelska at al., 2011].
} 
lected medical communities in the Podlasie Region clearly indicate the need for implementation of e-health to the health system. In their opinion, e-health is the main condition for the development of the health system as well as individual medical facilities. As barriers to the quality of the relationships between health care facilities and patients were indicated:

- financial barriers,

- mental barriers,

- infrastructural barriers,

- the lack of knowledge about e-health,

- the generation gap.

It was emphasized that the changes in the health care system are combined with high costs. Owners of private medical practices are concerned that most of the costs associated with the implementation of e-health will have to be paid from their own resources. In the opinion of the respondents, investments in e-health require big expenses, and return on investment is not always followed in the short term. In addition, in the opinion of health care managers, computerization and the use of IT is reflected in savings as a rule.

Mental barriers were recognized as essential limitations of e-health development. Health care employees, but often also managers of medical facilities are not fully able to identify specific and long-term benefits connected with the use of e-health. Knowledge potential of the medical communities about e-health has been assessed at an even lower level, because it is often limited to the internal processes involving advanced information technology in individual health care facilities.

An opinion was expressed that e-health directly affects the quality of patient care, but it is limited by the need to implement the security system. It is an important premise in the respondents' opinion to have specific systemic solutions when implementing ehealth.

The generation gap was recognized as particularly important. According to representatives of health care, this type of limitation concerns both patients and medical personnel, including doctors. Successful implementation of e-health is connected not only with the awareness of changes, but also with specific skills. It was emphasized that in an aging society it can be a major challenge.

Among the barriers limiting the benefits for patients resulting from e-health also organizational barriers were identified, since the implementation of e-health requires:

- an increase in the level of competence of medical personnel within e-health,

- clear division of duties,

- modernization of the infrastructure,

- creation of a uniform system of administrative supervision within e-health,

- $\quad$ the need to improve the information system about e-health.

Representatives of medical communities recognize the need for changes in the health care system based on the implementation of the e-health process. It should be emphasized that mental and awareness factors have been identified as the main barriers to the implementation process in the first place, rather than financial determinants. 


\section{Barriers to e-health in the opinion of personnel and patients ${ }^{4}$}

Patients as customers of the health care system have clear expectations as to the service level, but also to the organization of the service system in the health care facility. Civilization conditions make the information storage devices become more common. Secondly, people manage their time consciously. A characteristic feature of the quality of patient care is not only a competent service, but quick access to medical services.

Studies of patients in the Podlasie Province indicate very strong interest in the Internet - us much as $82 \%$ with Internet access use it every day. This high rate is generated mainly by young people. Most patients search information online about diseases and their symptoms $(74 \%)$. Almost half of them check surgery hours of the doctors using the Internet (48\%). Studies show that the Internet or e-mail is almost not used to communicate (to consult) with a doctor or other specialists in health matters (only $2 \%$ of respondents admit to it) (see Figure 2.).

FIGURE 2.

The use of the Internet by patients and e-mail in order to arrange a medical appointment

Do you use the Internet or e-mail in order to arrange a medical appointment:

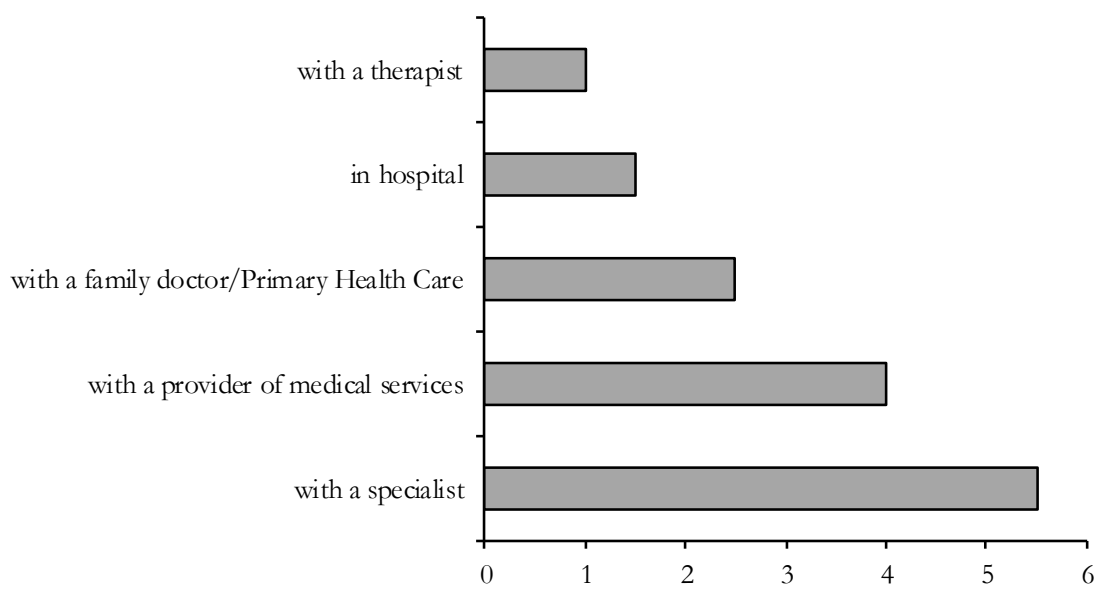

Source: [Widelska at al., p. 74].

Also the doctor (in a clinic or hospital) rarely uses a computer to transfer health information to the patient, for example relating to the description of the treatment or explanation of symptoms of the disease. Only $5 \%$ of respondents reported that such a fact occurred.

\footnotetext{
2011].

${ }^{4}$ Based on the survey (PAPI) conducted among 200 patients of the Podlasie Province [Widelska at al,
} 
The vast majority of respondents believe that universal access to computers and the Internet helps in maintaining health $(74.5 \%$ of respondents think that), helps to improve the health care system (78.5\% of respondents) and facilitates contact with health service and other providers of health care services. In this area, it is clear that patients with higher education are much more enthusiastic about e-health than those with primary education (see Figure 3.).

FIGURE 3.

The areas where the use of a computer and the Internet by a patient causes changes

Where does the use of a computer and the Internet cause changes?

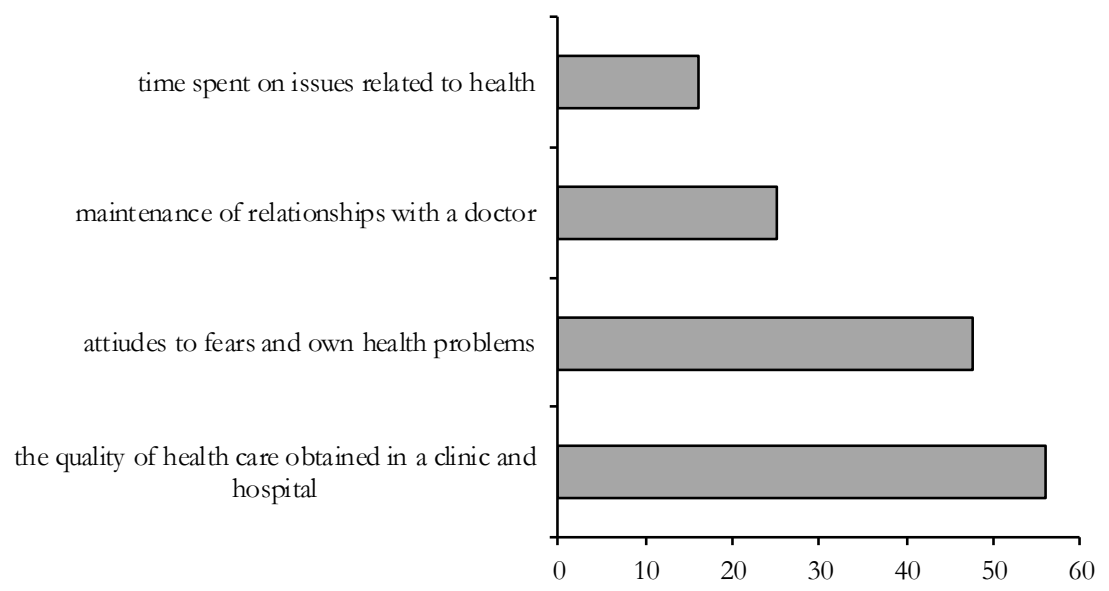

Source: [Widelska at al., p. 76].

Patients in connection with the intensive use of a computer and the Internet see many benefits of e-health to the quality of health care, including the impact on the attitudes to their own health problems and even relationships with their doctor.

The presented results of the research show that marketing barriers to e-health have a twofold source. The first one are the gaps in the healthcare system. Patients express their opinion on the current state of e-health and its possible impact on the extent of their needs from the perspective of the current situation in the whole system. The second source is the level of their knowledge of e-health. Patients do not have an organized system of information on this sphere of the health care system. The knowledge of e-health seems to be superficial and general.

\section{Conclusions}

As the example of the Podlaskie Province shows, solutions in e-health are consequently to serve patients. It is a basic premise for analyzing examined field of health 
care in terms of a marketing undertaking. This results from taking into account the social needs in health care and the factors that cause major changes in their area. The implemented scope of innovation is also significant. Also the need for changes in the health care system with the use of broadly defined processes of e-health is declared.

E-health is not only high costs and the expectation of long-term benefits. It is primarily an undertaking, the development of which is dependent on overcoming mental and information barriers. This concerns both the representatives of the medical communities, as well as patients. The second group of these stakeholder declare their readiness to changes, however, a limited information system about e-health does not allow a full assessment.

\section{Bibliography}

Benchmarking ICT Use among General Practitioners in Europe 2007, Country Profile: Poland, 2007, EC, Empirica.

Communication From the Commision to the Council, the European Parliament the European Economic and Social Committee of the Regions. eHealth Making Healthcare Better for the European Citizens: An Action Plan for a European Health Area, 2004, Brussels.

E-health for a Healtbier Europe! - Opportunities for a Better use of Healthcare Resources, 2009, The Ministry of Health and Social Affairs in Sweden, Gartner.

Europe's Digital Competitiveness Report 2010, 2010, European Commission.

Podrecznik dobrych praktyle E-zdrowie. Wyzwania regionalne i ich oddziatywanie, [Good Practice Guide E-Health. Regional challenges and their impact], 2007, the study in the project SIRMA, Tarnów.

Stanisz-Busch E., 2010, Podstany zarzadzania marketingowego w placónce medycznej [Fundamentals of Marketing Management in a Medical Facility], Wolters Kluwer Polska, Warszawa 2010.

The Socio-economic Impact of Interoperable Electronic Health Record(EHR) and ePrescribing Systems in Europe and beyond. Final Study Report, 2009, EC, Information Society and Media.

Widelska U., Dębkowska K., Michalczuk G., Warelis A., Raczkowski K., Raczkowska U., 2011, Badanie obszaru e-zdrowie projektu E-Podlaskie - kierunki rozwoju spoteczeństwa informacyjnego. Raport koncony [Research on the Area of E-health of the Project E-Podlaskie Directions of Development of Information Society. Final report], University of Bialystok, Biakystok. 